\section{STUDIES OF POPULATION CHANGES}

A MONG the papers read before the American Philosophical Society at its mid-winter meeting, February 19-20, 1943 (Proc. Amer. Phil. Soc., 87 , No. 2, August 16, 1943) is one by F. W. Notestein of the Office of Population Research, Princeton University, on "Some Implications of Population Change for Post-War Europe". Mr. Notestein points out that we have been living in a unique period of the world's demographic history - a period of unparalleled population growth, which in Western Europe is drawing to a close. After discussing the fundamentals of population change, he applies general principles based on the vital trends of the inter-war period to derive age schedules of fertility and mortality for the future, from which he and his colleagues have constructed a series of population projections for the years 1940-70 for the U.S.S.R. and each European nation as of the 1937 boundaries. The fundamental assumptions are: (1) that the future course of mortality and fertility will represent an orderly development of the trends of the post-war period; (2) that there will be no international migration ; and (3) that there is no war.

These projections indicate that the north-western and central region will reach its maximum population by 1950; in England and Wales, Sweden, Estonia, France, Belgium and Switzerland the maximum will be attained or passed by 1945 ; in 1955 by Scotland, Latvia, Finland, Norway, Germany, Austria and Czechoslovakia. While the effect of the War cannot at present be estimated, assuming the losses in the present conflict are proportional in each age-group to those of the War of 1914-18, it can be computed that the German population of 1950 will be about 25 millions less because of the decline in fertility and 10 millions less because of the losses of two wars. Accordingly, Mr. Notestein suggests that throughout this region society must be reoriented towards the interests of children, probably detracting somewhat from the current preoccupation with the needs of the aged. It may also have to be less oriented towards strictly individualistic values and more toward those of the group.

In southern and eastern Europe the principal characteristic of the period 1940-70 is a rapid increase in the persons of working age, and accordingly throughout the period there will be constant danger of pressure of population on developed resources in a region already suffering from pressure of population on its predominantly agricultural economy. Such pressures must be relieved in this region of deep hatreds if strife is to be avoided. Prompt relief, it is claimed, can only come from two sources : absorption. of the region by the Soviet Union, which has ample resources and an enviable record in dealing with ethnic heterogeneity, or an economic and political solution by the Western Powers. The latter would be impossible if a series of small sovereign States were set up. The solution lies in the creation of a wide trade area of relatively free migration into which outside capital and skills are brought to foster industrialization and urbanization.

In contrast with the other regions, the Soviet Union faces rapid growth in all sections of its popula. tion more than five years of age, and this growth in population will probably be matched with a growth in power. The Soviet Union has ample natural resources to support its prospective population within its present boundaries, and Mr. Notestein concludes that it is difficult to escape the view that the Soviet Union in the coming decades will be the strongest single Power in the world. The United States, in his view, could not wisely stand apart from an association for collective security based on the mutual selfinterest of the community of nations.

Included in this symposium of papers on post-war problems is a paper by the late Prof. Franz Boas of Columbia University, which was read before the Society on November 21, 1942. In this paper, "Individual, Family, Population and Race", are briefly summarized the results of an investigation of a number of highly mixed populations, like those of the eastern large cities of the United States, of other groups more uniform because members of a welldefined national group, and by contrast isolated groups that had for long intermarried among themselves, such as the Scandinavians of the Faroe Islands, the East Siberian tribes of the Chukchee Peninsula, Chippeway Indians of a few communities that have for long intermarried, the Bastards of South Africa, the Pitcairn islanders and a mixed Malay Dutch population from Kissar.

The results of the study demonstrate a sharp cleavage between the isolated groups and the two other groups, and Boas infers that there is no human group in existence which is so uniform either in fraternal groups or in family lines that any one individual can be considered as a representative of the group. In other words, there are no characteristics known that would allow us to claim that individual characteristics are determined by traits common to the whole group. The component individuals of any group vary markedly among themselves, and 'race' does not determine human behaviour. While Boas does not claim that it has been proved that biologically or genetically determined characteristics are exactly the same in all populations, he maintains that every known population, no matter on what princip'es it is selected, shows a wide degree of variation of forms; that no pure human race exists, and that behaviour is much more rigidly controlled by natural and social environment than by descent.

\section{FORTHCOMING EVENTS}

(Meeings marked with an asterisk * are open to the public)

\section{Saturday, January 1}

ROYAL INSTITUTION (at 21 Albemarle Street, London, W.1), at 2.30 p.m. - Prof. E. N. da C. Andrade, F.R.S.: "Vibrations and Waves", 3 : "Sound Waves".

\section{Monday, January 3}

ROYal Ggographicai Socieny (at Kensington Gore, London, S.W.7), at 2.30 p.m.-Mrs. Reginald Wyndham: "In the Netherlands Indies", with Kodachrome and other Films (Christmas Lecture for Young People).

SOCIETY OF CHEMTCAX INDUSTRY (LONDON SECTION AND FOOD GROUP) (at the London School of Hygiene and Tropical Medicine Keppel Street, Gower Street, London, W.C.1), at 2.30 p.m.-P rof C. R. Harington, F.R.S.: "The Contribution of Chemistry to Immunology" (Jubilee Memorial Lect ure).

\section{Tuesday, January 4}

ROYAI INSTITUTION (at 21 Albemarle Street, London, W.1), at 2.30 p.m.-Prof. E. N. da C. Andrade, F.R.S.: "Vibrations and Waves", 4 : "Visible Light"."

Tuesday, January 4-Wednesday, January 5

AGRICULTURAI EDUCATION Assocration (at the London School of Hygiene and Tropical Medicine, Keppel Street, Gower Street, London, W.C.1). - - Half-yearly Conference.

\section{Tuesday, January 4}

At 9.30 a.m. (Agriculture Section), - Dr. John Hammond: "The Breeding of Cattle for Milk or Meat"; Reports by Dr. S. Bartlett and Dr. J. Edwards on "The Reading and Cambridge Artifleial Insemination Centres". 